\title{
Expression of Histo-Blood Group A Type 1, 2 and 3 Antigens in Normal Skin and Extramammary Paget's Disease
}

\author{
Aki Tanaka ${ }^{1}$, Akihiko Kimura ${ }^{2}$, Yuki Yamamoto ${ }^{1}$, Koji Uede $^{1}$ and Fukumi Furukawa ${ }^{1}$ \\ ${ }^{1}$ Department of Dermatology, Wakayama Medical University and ${ }^{2}$ Department of Forensic Medicine, Wakayama Medical \\ University, Wakayama City, Wakayama, Japan
}

Received May 27, 2008; accepted October 1, 2008; published online October 30, 2008

The distribution of histo-blood group A type 1, 2 and 3 antigens was investigated using immunohistochemistry in normal human skin and extramammary Paget's disease (EMPD). We used monoclonal antibodies (mAbs) Bioclone-A (BA) and AR-1, which react with histo-blood group $A$ type 1/2, and type 3 antigens, respectively. We found that $A$ type 1, 2 and 3 antigens were expressed in the upper layer of the epidermis. We also found that the duct cells of the eccrine glands expressed $A$ type $1 / 2$ antigens and $A$ type 3 antigens regardless of secretor status. The dark cells of the eccrine glands expressed $A$ type 1, 2 and 3 antigens from A blood group secretors, but not from non-secretors. Apocrine glands, hair follicles and sebaceous glands did not express these antigens. Since these antigens were localized in the eccrine glands, we examined the possibility of a skin tumor marker. Interestingly, 7 out of 16 extramammary Paget's disease cases were immunopositive for these antigens. Six cases were accompanied by dermal invasion. Five cases without dermal invasion were immunonegative against these antigens. These results suggest that the expression of histoblood group A antigens in EMPD are associated with a poor histopathological prognosis.

Key words: histo-blood group A type 1/2 antigens, histo-blood group A type 3 antigens, eccrine glands, extramammary Paget's disease

\section{Introduction}

The ABH determinants are oligosaccharides composed of L-fucose, D-galactose, and D-N-acetylgalactosamine [5, 31]. Clausen and Hakomori [3] proposed the concept of an inner and a peripheral core in these oligosaccharides. The core extending from the glycosylation site is designated as the inner core, while the peripheral disaccharides, which serve as the actual precursor structures for various glycosyltransferases, are designated as the peripheral core. Most of the blood group-related transferases, which terminate the chain elongation process, are among the precursor structures included in the peripheral core. It is thus well known that the antigenicity of the ABH determinants is influenced by the peripheral core structure. There are four types of peripheral core structures known to carry $\mathrm{ABH}$ activity: type 1:

Correspondence to: Aki Tanaka, M.D., Department of Dermatology, Wakayama Medical University, 811-1 Kimiidera, Wakayama City, Wakayama 641-0012, Japan. E-mail: akis@wakayama-med.ac.jp
Gal $\beta 1 \rightarrow 3 \mathrm{GlcNAc} \beta 1 \rightarrow \mathrm{R}$, type $2:$ Gal $\beta 1 \rightarrow 4 \mathrm{GlcNAc} \beta 1 \rightarrow \mathrm{R}$, type 3: Gal $\beta 1 \rightarrow 3$ GalNAc $\alpha 1 \rightarrow \mathrm{R}$, and type 4: Gal $\beta 1$ $\rightarrow 3$ GalNAc $\beta 1 \rightarrow \mathrm{R}$ [3]. The peripheral core disaccharides are differentially distributed onto various human tissues and body fluids. Type 1 antigens are widely expressed on endodermally-derived tissues such as lining epithelia and glandular epithelia. Type 2 antigens are found mainly on ecto- or mesodermally-derived tissues, including erythrocytes [17]. Type 3 and 4 antigens are found on ecto- or endodermally-derived tissues, including the salivary glands and kidneys [3]. Thus, ABH antigens are present not only on erythrocytes, but also on various organs such as the salivary glands and kidneys [1,9], hence they are called histo-blood group $\mathrm{ABH}$ antigens.

Interestingly, these antigens are seen in the normal epidermis and in the epidermal appendages [10, 16, 32]. England et al. [10] found that isoantigens A, B, and H (O) were detected in the stratum corneum, stratum granulosum, stratum spinosum, acrosyringium, keratogenous zone of hair follicle, eccrine duct and eccrine gland. 
On the other hand, the alteration of cell-surface blood group antigens during malignant transformation is a wellknown phenomenon observed in various tumor conditions $[6,14,22]$. This occurs in carcinomas of the oral epithelium [4], the stomach [11], the colon $[11,25]$, the pancreas [7, 12], the lung [24], the urinary bladder [21] and the thyroid glands [12]. To the best of our knowledge, this phenomenon has not been investigated in extramammary Paget's disease (EMPD)

In this study, we investigated the immunohistochemical distribution of peripheral core isotypes of histo-blood group antigens in normal human skin and EMPD to assess the usefulness of the altered expression of histo-blood group antigens for the diagnosis and prognosis of EMPD.

\section{Materials and Methods}

\section{Specimens}

Normal skin samples consisted of 11 patients (individual age ranged from 0 to 87 , mean age: 46.9 years, male to female ratio: 3:8). The samples from $\mathrm{O}$ and $\mathrm{B}$ blood group individuals were used as negative controls.

Neoplastic samples were selected from routine specimens of 16 patients seen in our hospital from 1984 to 2006 . These tissues were obtained from skin biopsies or surgery. The individual ages ranged from 59 to 88 (mean age: 76 years, male to female ratio: 11:5). The blood groups of these samples were either A or AB. All specimens were fixed in $4 \%$ buffered formaldehyde, and the paraffin-embedded sections were stained with hematoxylin-eosin (HE). All neoplasms were histopathologically diagnosed by at least 3 dermatologists or pathologists, and were divided into five groups using the $\mathrm{pT}$ classification according to the tentative classification system proposed by the Japanese Skin Cancer Society [23]. A secretor is defined as a person who secretes their histo-blood group antigens into their body fluids and secretions, and is under the control of the secretor (Se) geneencoded $\alpha 1,2$-fucosyltransferase (FUT II). A non-secretor is defined as a person who does not express functional FUT II, and does not secrete their histo-blood group antigens into their body fluids or secretions. Secretor status was determined by staining of the eccrine glands using immunohistochemistry. Those samples in which both duct cells and dark cells of the eccrine glands were immunostained were designated as secretors. Those samples in which only duct cells were immunostained were designated as non-secretors. This study was approved by the ethics committee of Wakayama Medical University.

\section{Antibodies}

The mouse monoclonal antibody $(\mathrm{mAb})$ directed against A type 3 antigens (AR-1: IgM) was produced as described previously [20]. The specificity of AR-1 was determined by thin layer chromatographic-immunostaining of glycosphingolipids extracted from blood group A erythrocyte membranes. Their specificity was confirmed through comparison with authentic anti-type 3 A mAb TH-1 [2].
MAb Bioclone Anti-A (BA) was purchased from Ortho Clinical Diagnosis (Raritan, NJ). MAb AR-1 was then evaluated and used on the type 3 peripheral core isotypes, and $\mathrm{mAb} B A$ was evaluated and used on the type $1 / 2$ peripheral core isotypes.

Anti-human milk fat globule 1 (anti-HMFG1) antibody (clone 1.10.F3), a marker for apocrine differentiation, was purchased from Abcam (Cambridge, MA).

\section{Tissue processing}

The specimens were fixed in formaldehyde for routine histopathology. Six- $\mu \mathrm{m}$ sections were deparaffinized, immersed in $3 \% \mathrm{H}_{2} \mathrm{O}_{2}$ for $5 \mathrm{~min}$, and incubated with each $\mathrm{mAb}$ (AR-1, 1:20; BA, 1:100 and anti-HMFG1, 1:20) for $60 \mathrm{~min}$ at room temperature (RT) after rinsing with PBS. Sections were incubated with goat anti-mouse immunoglobulins conjugated to a peroxidase labeled dextran polymer (EnVision $+^{\mathrm{TM}}$, Dako Cytomation, Kyoto, Japan) for 30 $\mathrm{min}$ at RT. Positive reactions were then visualized with 3amino-9-ethylcarbazole, and counterstained with Mayer's hematoxylin.

The blood group-specific reactivity of mAb BA and AR-1 was confirmed by the absorption of antibodies with excess amounts of A or O blood group red cells, as described previously [20].

The stained specimens were evaluated by three blinded investigators without prior knowledge of the clinical data of the patients.

\section{Statistical analysis}

The samples were histopathologically divided into two groups, non-invasive and invasive, according to the pT classification [23]. T1 (where the neoplastic cells are located in the epidermis) is defined as non-invasive, whereas T2 (where the neoplastic cells are located in the dermis associated with microinvasion), T3 (where the neoplasm forms nodules without vessel invasion) and T4 (where the neoplasm forms nodules with vessel invasion) are defined as invasive. The $2 \times 2$ cross-categorized frequency data were analyzed using Fisher's exact test. We evaluated the

Table 1. Expression of A type 1,2 and 3 antigens in the appendages

\begin{tabular}{llcc}
\hline & & AR-1 & BA \\
\hline eccrine glands & intraepidermal duct cells & + & + \\
& intradermal duct cells & + & + \\
& secretory cells & & \\
& dark cells & $+*$ & $+*$ \\
& clear cells & - & - \\
luminal secretions & $+*$ & $+^{*}$ \\
apocrine glands & duct cells & - & - \\
& secretory cells & - & - \\
luminal secretions & - & - \\
sebaceous glands & & - & - \\
\hline
\end{tabular}

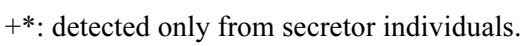


relationship between histo-blood group antigen expression and the non-invasive and invasive groups using the online facility at http://faculty.vassar.edu/lowry/VassarStats.html. A $P<0.05$ was considered to be statistically significant.

\section{Results}

\section{Localization of peripheral core-isotypes of histo-blood group antigens in normal skin}

In the normal skin tissues, the localization of A type 1/ 2 antigens as defined by mAb BA and A type 3 antigens as defined by mAb AR-1 was investigated immunohistochem- ically, and the results are summarized in Table 1 . The upper layer of the epidermis expressed A type 1/2 antigens (Fig. 1A, E) and A type 3 antigens (Fig. 1B, G). The duct cells of the eccrine glands expressed A type 1/2 antigens (Fig. 1C, F, I) and A type 3 antigens (Fig. 1D, H, K) regardless of their secretor status. The dark cells of the eccrine glands expressed A type 1/2 antigens (Fig. 1C, J), and 3 antigens (Fig. 1D, L) from A blood group secretors but not from non-secretors (Fig. 1F, H). Duct cells positive for A type $1 / 2$ antigens and A type 3 antigens showed circumferential luminal immunostaining (Fig. 1C, D, F, H, I, K). Dark cells positive for A type 1, 2 and 3 antigens showed diffuse
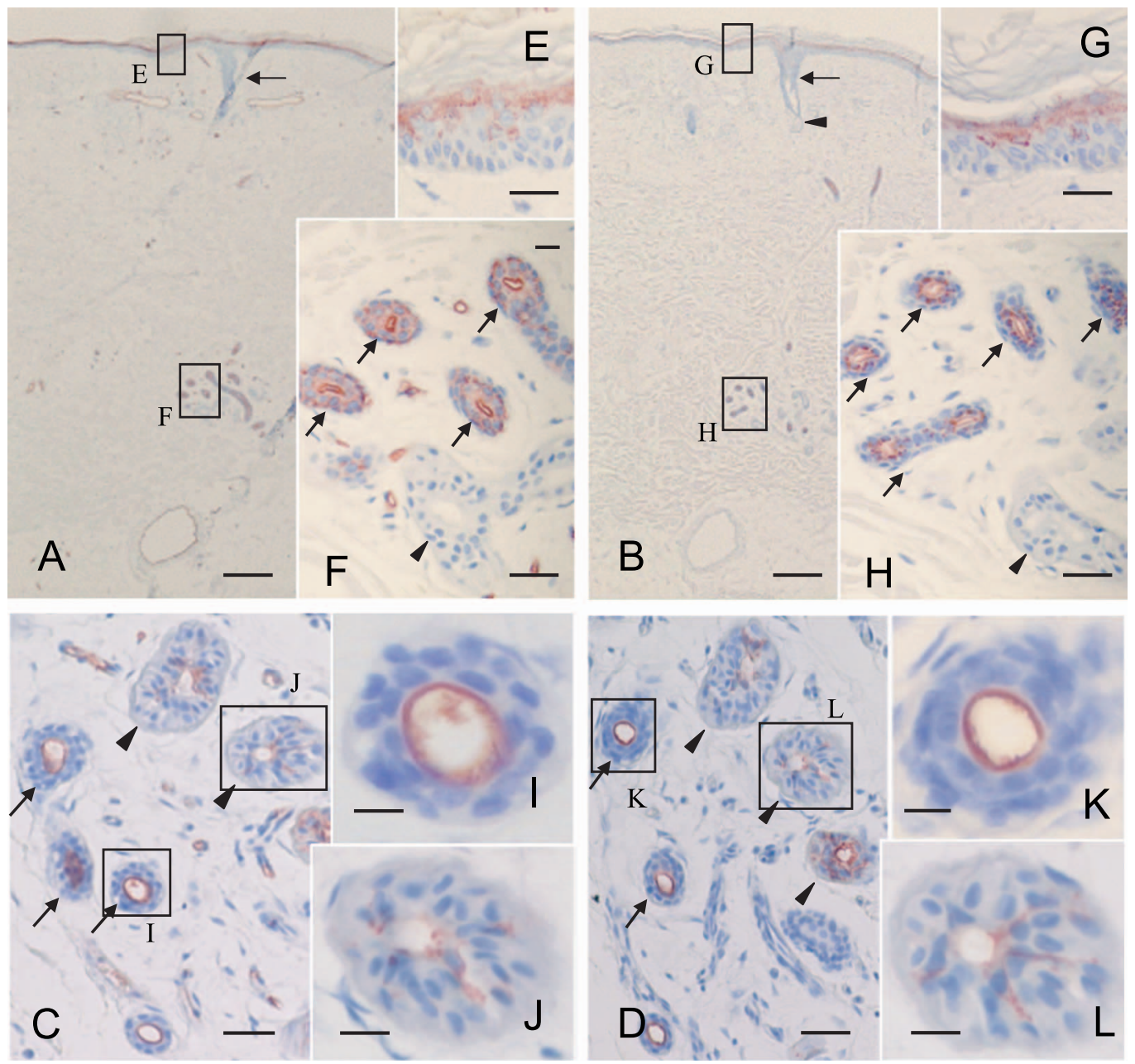

Fig. 1. Sections from blood group $A$ non-secretor $(\mathbf{A}$ and $\mathbf{B})$ and secretor individuals $(\mathbf{C}$ and $\mathbf{D})$ were immunostained by $\mathrm{mAb} B A(\mathbf{A}$ and $\mathbf{C})$ or AR-1 (B and D). In the specimen from the non-secretor (A), A type 1/2 antigens as defined by mAb BA were expressed in the upper layer of the epidermis (E) and the duct cells of the inner layer of the eccrine glands (F; arrows), but not in the dark cells (F; closed arrowheads). In the specimen from the secretor $(\mathbf{C})$, A type 1/2 antigens were localized in the dark cells (C; closed arrowheads) and duct cells (C; arrows). Areas indicated by the boxes $(\mathbf{E}, \mathbf{F}, \mathbf{I}$ and $\mathbf{J})$ in $\mathbf{A}$ and $\mathbf{C}$ are depicted at a higher magnification in $\mathbf{E}, \mathbf{F}, \mathbf{I}$ and $\mathbf{J}$, respectively. In the specimen from the nonsecretor (B), A type 3 antigens as defined by mAb AR-1 were also expressed in the upper layer of the epidermis (G) and the duct cells of the eccrine glands (H; arrows), but not in the dark cells (H; closed arrowheads). In the specimen from the secretor (D), A type 3 antigens were localized in the dark cells (D; closed arrowheads) and duct cells (D; arrows). The areas indicated by the boxes $(\mathbf{G}, \mathbf{H}, \mathbf{K}$ and $\mathbf{L})$ in $\mathbf{B}$ and $\mathbf{D}$ are depicted at a higher magnification in $\mathbf{G}, \mathbf{H}, \mathbf{K}$ and $\mathbf{L}$, respectively. Hair follicles (A, B; arrows) and sebaceous glands (B; closed arrowhead) were immunonegative. Note that strong immunostaining was observed in the luminal cells of the eccrine duct (C, D, F, H: arrows, I, K). Bars $=500 \mu \mathrm{m}(\mathbf{A}$ and $\mathbf{B}), 50 \mu \mathrm{m}(\mathbf{C}-\mathbf{H}), 15 \mu \mathrm{m}(\mathbf{I}-\mathbf{L})$, and $200 \mu \mathrm{m}(\mathbf{M})$. 

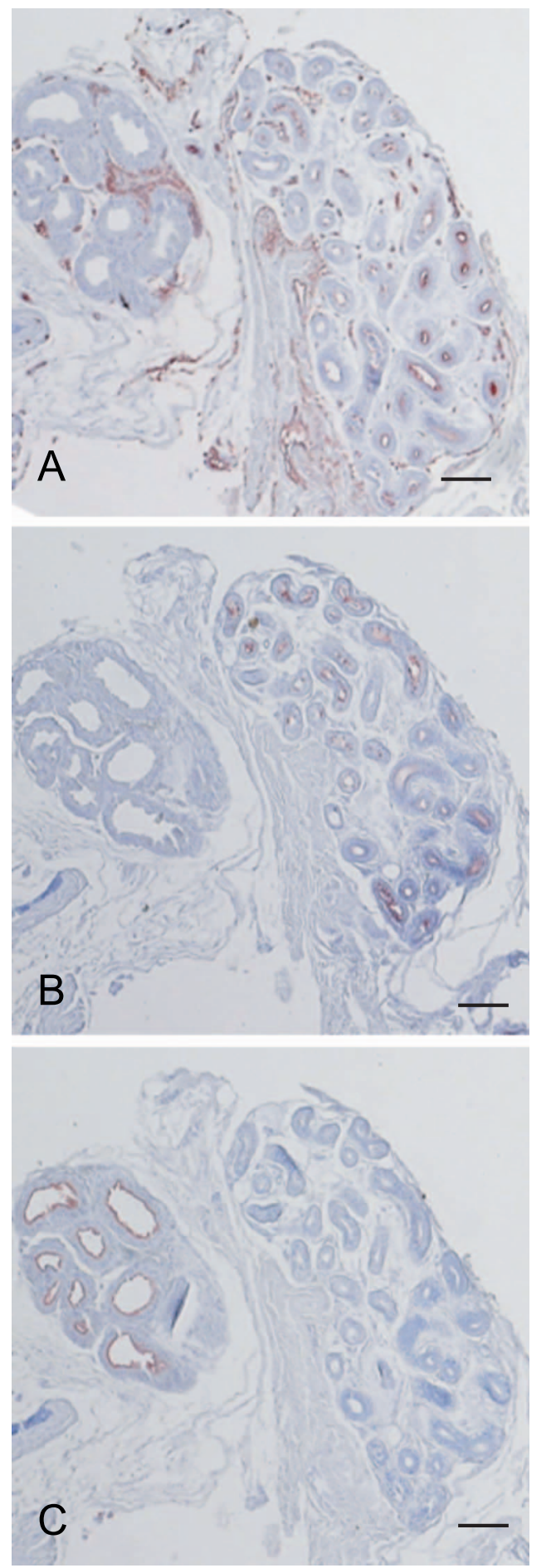

Fig. 2. Localization of A type 1, 2 and 3 antigens and human milk fat globule 1 (HMFG1) in eccrine and apocrine glands. A, B and $\mathbf{C}$ are serial sections from a secretor blood group $\mathrm{AB}$ individual. $\mathrm{A}$ type 1/2 antigens (A) and A type 3 antigens (B) were expressed in the eccrine glands (right side), whereas HMFG1 (C) was expressed only in the apocrine glands (left side). A type $1 / 2$ antigens were both expressed in the blood vessels of the stroma (A). Bar $=400 \mu \mathrm{m}$ (A-C).
Table 2. Expression of A type 1,2 and 3 antigens and human milk fat globule 1 in extramammary Paget's disease patients

\begin{tabular}{|c|c|c|c|c|c|c|c|}
\hline case & $\begin{array}{c}\mathrm{pT} \\
\text { classification }\end{array}$ & $\begin{array}{l}\text { lymph node } \\
\text { metastasis }\end{array}$ & AR-1 & BA & HMFG & $\begin{array}{l}\text { blood } \\
\text { group }\end{array}$ & $\begin{array}{l}\text { secretor } \\
\text { status }\end{array}$ \\
\hline 1 & $\mathrm{~T} 1$ & N/A & - & - & - & A & $\mathrm{s}^{*}$ \\
\hline 2 & $\mathrm{~T} 1$ & N/A & - & - & + & A & $\mathrm{s}^{*}$ \\
\hline 3 & $\mathrm{~T} 1$ & N/A & - & - & - & $\mathrm{AB}$ & $\mathrm{ns}^{* *}$ \\
\hline 4 & $\mathrm{~T} 1$ & N/A & - & - & - & A & N/A \\
\hline 5 & $\mathrm{~T} 1$ & N/A & - & - & - & A & $\mathrm{s}^{*}$ \\
\hline 6 & $\mathrm{~T} 1^{\dagger}$ & $+\$$ & + & + & + & A & $\mathrm{s}^{*}$ \\
\hline 7 & $\begin{array}{c}\mathrm{T} 1 \\
\text { (adenoid }^{+\dagger} \text { ) }\end{array}$ & N/A & - & - & - & $\mathrm{AB}$ & $\mathrm{ns}^{* *}$ \\
\hline 8 & $\begin{array}{c}\mathrm{T} 1 \\
\text { (adenoid }^{\dagger \dagger} \text { ) }\end{array}$ & N/A & - & - & - & A & $\mathrm{s}^{*}$ \\
\hline 9 & $\mathrm{~T} 2$ & N/A & + & + & + & A & $\mathrm{s}^{*}$ \\
\hline 10 & $\mathrm{~T} 2$ & N/A & + & + & - & A & $\mathrm{s}^{*}$ \\
\hline 11 & $\mathrm{~T} 2$ & - & + & + & - & A & $\mathrm{s}^{*}$ \\
\hline 12 & $\mathrm{~T} 2$ & N/A & + & + & - & A & $\mathrm{s}^{*}$ \\
\hline 13 & $\mathrm{~T} 3$ & $++\phi$ & + & + & + & $\mathrm{AB}$ & $\mathrm{s}^{*}$ \\
\hline 14 & $\mathrm{~T} 4$ & $++\phi$ & + & + & + & A & $\mathrm{s}^{*}$ \\
\hline 15 & $\mathrm{~T} 4$ & $\begin{array}{l}+\dagger \text {, lung } \\
\text { metsatasis }\end{array}$ & - & - & + & A & $\mathrm{ns}^{* *}$ \\
\hline 16 & $\mathrm{~T} 4$ & & - & - & - & A & $\mathrm{s}^{*}$ \\
\hline
\end{tabular}

N/A: not applicable, $\mathrm{s}^{*}$ : secretor individuals, $\mathrm{ns}^{* *}$ : non-secretor individuals, $+^{\dagger}$ : axillary region, $+^{+\dagger}$ : inguinal region. adenoid ${ }^{+\dagger}$ : neoplastic cells showed adenoid proliferation. Note: Cases 9-16 showed dermal invasion.

cytoplasmic and membrane immunostaining (Fig. 1C, D, J, L). Hair follicles and sebaceous glands did not express these histo-blood group antigens (Fig. 1A, B). The immunostaining was inhibited by the preabsorption of $\mathrm{mAb} B A$ and $\mathrm{mAb}$ AR-1 with blood group A red cells, but not with blood group $\mathrm{O}$ red cells (data not shown). Immunoreactivity was not detected in any of the normal skin samples from $\mathrm{O}$ or $\mathrm{B}$ individuals (data not shown). These facts confirmed the A blood group-specific reactivity of mAb BA and mAb AR-1.

The apocrine glands expressed human milk fat globule 1 (HMFG1) (Fig. 2C). A type 1, 2 and 3 antigens were expressed only in the eccrine gland (right side, Fig. 2A, B) and not the apocrine gland (left side, Fig. 2A, B). A type 1/2 antigens were expressed in both the blood vessels of the stroma (Fig. 2A) and the eccrine gland (right side, Fig. 2A). Therefore, the eccrine glands can be distinguished from the apocrine glands by the expression of histo-blood group antigens.

\section{Localization of peripheral core-isotypes of histo-blood group antigens in extramammary Paget's disease}

We investigated the expression of peripheral coreisotypes of histo-blood group antigens and HMFG1 in EMPD (data summarized in Table 2). Seven (43.8\%) out of 16 EMPD cases expressed histo-blood group antigens (Fig. 3C-F) (Table 2; Case 6 and Cases 9-14). In 6 out of 7 histo-blood group antigen positive cases, neoplasms were located in the genital area and were accompanied by dermal invasion. In the remaining histo-blood group antigen posi- 

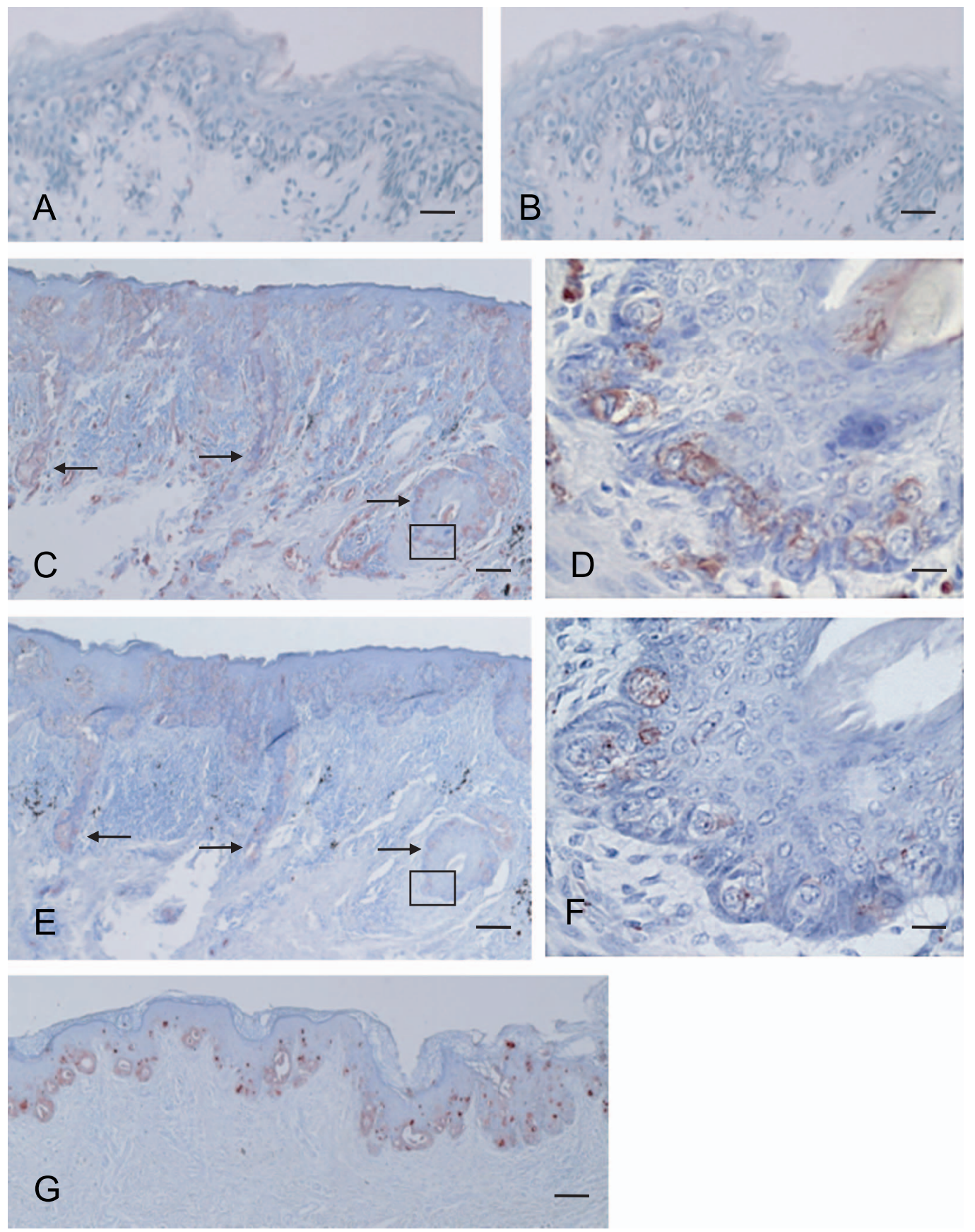

Fig. 3. Expression of A type 1-3 and HMFG1 in extramammary Paget's disease (EMPD). A type 1, 2 and 3 antigens were not detected in the sections from the specimen (case 4 in Table 2) without dermal invasion by mAb BA (A) and AR-1 (B). In sections from the specimen (case 9 in Table 2) accompanied by dermal invasion, A type 1/2 and A type 3 antigens were detected by mAb BA (C) and AR-1 (E), respectively. Arrows in $\mathbf{C}$ and $\mathbf{E}$ indicate the regions of dermal invasion by the neoplastic cells. Areas indicated by the boxes in $\mathbf{C}$ and $\mathbf{E}$ are depicted at a higher magnification in $\mathbf{D}$ and $\mathbf{F}$, respectively. HMFG1 was localized in a different and distinct region from the histo-blood antigens in the epidermis (G). Bars $=50 \mu \mathrm{m}$ (A and $\mathbf{B}), 100 \mu \mathrm{m}(\mathbf{C}, \mathbf{E}$ and $\mathbf{G}), 15 \mu \mathrm{m}(\mathbf{D}$ and $\mathbf{F})$.

tive case (Case 6 in Table 2), the neoplasm was located in the axillary region. Five cases without dermal invasion (Cases $1-5$ in Table 2) were not immunoreactive to these mAbs (Fig. 3A, B). A type 1/2 antigens and A type 3 antigens were localized in the same region. We found that histo-blood group antigens expression was significantly associated with the invasive group (stage pT2 to pT4) as compared with the non-invasive group (stage $\mathrm{pT} 1)(\mathrm{p}=0.04$, Fisher's exact test).

HMFG1 and histo-blood group antigens were immunopositive on distinct regions in EMPD tissues (Fig. 3G). Some neoplastic cells in EMPD expressed either histo-blood 
group antigens or HMFG1, whereas other cells expressed neither of these two antigens.

\section{Discussion}

The eccrine ducts are sometimes histopathologically indistinguishable from apocrine ducts and their tumors; however, they are different in size, structure, distribution and function. Therefore, there have been many studies to differentiate them and their tumors [27, 28, 30]. To address the issue, many immunohistochemical markers have been found such as the $70 \mathrm{kDa}$ glycoprotein purified from human milk fat globule membrane (MFGM-gp 70) [15] and HMFG1 [29]. Imam et al. reported that the antibody raised against MFGM-gp 70 reacted with the apocrine glands, but not with the eccrine glands [15]. de Viragh et al. also reported the apocrine gland-specific expression of HMFG1 [29].

In this study, we immunostained skin samples with $\mathrm{mAb} \mathrm{BA}, \mathrm{mAb}$ AR-1 and anti-HMFG1 in order to differentiate between the apocrine and eccrine glands. A type $1 / 2$ antigens and $\mathrm{A}$ type 3 antigens were detected by $\mathrm{mAb} \mathrm{BA}$ and $\mathrm{mAb} A \mathrm{AR}-1$, respectively. We found that the duct cells of the inner layer in normal eccrine glands expressed A type 1, 2 and 3 antigens regardless of the secretor status. On the other hand, these antigens were expressed in the dark cells of the eccrine glands from secretors, but not non-secretors. These observations indicated that the dark cells of the eccrine glands expressed histo-blood group A type 1 and type 3 antigens, and that the duct cells expressed histo-blood group A type 2 and type 3 antigens. This can be attributed to the difference in the Se-gene dependency of each iso-type of the histo-blood group antigens. The expression of type 1 antigens is under the control of the Se-gene, and the expression of type 2 antigens is independent of the Se-gene. On the other hand, type 3 antigen expression can be either dependent or independent of the Se-gene [3, 13]. Histoblood group antigens were not expressed in the apocrine glands which expressed HMFG1 (Fig. 2C), suggesting that histo-blood group antigens are good makers for distinguishing between normal eccrine glands and apocrine glands.

Histo-blood group antigens can be found in various normal cells, mainly of the epithelial type. In carcinomas, the altered expression of various carbohydrate epitopes has been observed. Detailed clinicopathological studies have shown that differences in the survival rates of patients are related to the expression of histo-blood group antigens. Thus, certain histo-blood group antigens are not simply tumor markers, but may constitute part of the essential machinery to induce metastasis and invasiveness. Nakagoe et al. [18, 19] reported the presence of histo-blood group antigens in colorectal carcinomas, as well as the correlation between histo-blood group antigens and a poor prognosis for the patient. This is obvious in the distal colon, where histoblood group antigens are present up to the 10-14th week of gestation; after that, they disappear for the remaining period of postnatal life $[8,26]$. They then reappear malig- nantly transformed in the distal colon.

This study was conducted in order to differentiate between apocrine and eccrine glands to further define of their roles in EMPD. We used mAb BA and mAb AR-1 as the specific markers for eccrine glands. Both mAbs strongly reacted to the histo-blood group antigens in the EMPD. However, since AR-1 did not react to the blood vessels, the histo-blood group antigens in the tumor were detected more clearly by AR-1 as compared to mAb BA. In our study, 7 out of 16 EMPD specimens were immunopositive for histoblood group A type 1, 2 and 3 antigens. Six out of 7 immunopositive cases were accompanied by dermal invasion. The remaining immunopositive case was not accompanied by dermal invasion, but was located at the right axilla and genital region, which is termed multiple Paget's disease. This case was located in the axillary region. This case and the two other of the 6 dermal invasion cases were accompanied by inguinal lymph node metastasis. In other words, some of the neoplastic cells in EMPD express histo-blood group antigens normally expressed in eccrine glands. Furthermore, the histo-blood group antigen positive region of EMPD did not express HMFG1. Some neoplastic cells in EMPD expressed either histo-blood group antigens or HMFG1, and other cells expressed neither of these two antigens. The aberrant expression of histo-blood group antigens in EMPD is similar to the oncodevelopmental antigens expressed in colon carcinomas [19]. Although it is not clear where the histo-blood group antigens are expressed in the apocrine glands during the prenatal period, our data suggest that re- or neo-expression of histo-blood group antigens occurs in a continuous process.

In conclusion, histo-blood group antigens are specifically expressed in the eccrine glands, and therefore the eccrine glands can be distinguished from the apocrine glands by the expression of histo-blood group antigens. We found that EMPD accompanied by dermal invasion significantly expressed histo-blood group antigens, as compared to EMPD which did not have dermal invasion. Although additional investigation is required to elucidate the pathogenic mechanisms responsible for the expression of histo-blood group antigens in EMPD, these results suggest that the expression of histo-blood group antigens is related to a poor histopathological prognosis of EMPD.

\section{Acknowledgements}

We would like to thank Dr. Toshikazu Kondo (Department of Forensic Medicine, Wakayama Medical University) for valuable discussions and encouragement, and Dr. Mizuho Nosaka (Department of Forensic Medicine, Wakayama Medical University) for technical support and valuable comments.

\section{References}

1. Breimer, M. E. and Jovall, P. A. (1985) Structural characterization of a blood group A heptaglycosylceramide with globo-series 
structure. The major glycolipid based blood group A antigen of human kidney. FEBS Lett. 179; 165-172.

2. Clausen, H., Levery, S. B., Nudelman, E., Tsuchiya, S. and Hakomori, S. (1985) Repetitive A epitope (type 3 chain A) defined by blood group $\mathrm{A}_{1}$-specific monoclonal antibody TH-1: Chemical basis of qualitative $\mathrm{A}_{1}$ and $\mathrm{A}_{2}$ distinction. Proc. Natl. Acad. Sci. US A 82; 1199-1203.

3. Clausen, H. and Hakomori, S. (1989) ABH and related histoblood group antigens; immunochemical differences in carrier isotypes and their distribution. Vox Sang. 56; 1-20.

4. Dabelsteen, E., Graeam, N., Hakomori, S. and Young, W. W. Jr. (1983) Monoclonal antibodies in the diagnosis of epithelial premalignant lesions. Bull Cancer 70; 127-131.

5. Dabelsteen, E. and Gao, S. (2005) ABO blood-group antigens in oral cancer. J. Dent. Res. 84; 21-28.

6. Dall'Olio, F. (1996) Protein glycosylation in cancer biology: an overview. J. Clin. Mol. Pathol. 49; M126-M135.

7. Davidsohn, I., Ni, L. Y. and Stejskal, R. (1971) Tissue isoantigens A, B and $\mathrm{H}$ in carcinoma of the pancreas. Cancer Res. 31; 12441250.

8. Denk, H., Tappeiner, G. and Holzner, J. H. (1974) Blood group substances (BG) as carcinofetal antigens in carcinomas of the distal colon. Eur. J. Cancer 10; 487-490.

9. Donald, A. S. (1981) A-active trisaccharides isolated from A1 and A2 blood-group-specific glycoproteins. Eur. J. Biochem. 120; 243-249.

10. England, D. M., Solie, B. and Winkelmann, R. K. (1979) Isoantigens A, B, H in normal skin and tumors of the epidermal appendages. Arch. Pathol. Lab. Med. 103; 586-590.

11. Ernst, C., Thurin, J., Atkinson, B., Wurzel, H., Herlyn, M., Stromberg, N., Civin, C. and Koprowski, H. (1984) Monoclonal antibody localization of $\mathrm{A}$ and $\mathrm{B}$ isoantigens in normal and malignant fixed human tissues. Am. J. Pathol. 117; 451-461.

12. González-Cámpora, R., Gracía-Santana, J. A., Heras, M. M. J., Salaverri, C. O., Vázquez-Ramírez, F. J., Argueta-Manzano, O. E. and Galera-Davidson, H. (1998) Blood group antigens in differentiated thyroid neoplasms. Arch. Pathol. Lab. Med. 122; 957965.

13. Hakomori, S. (1995) Molecular basis for major human blood group antigens. In "Histo-Blood Group Antigens as TumorAssociated Carbohydrate Antigens and Ligands for Cell Adhesion”, vol. 6, ed. by J.-P. Cartron and P. Rouger, Plenum Press, New York, pp. 421-443.

14. Hakomori, S. (1999) Antigen structure and genetic basis of histoblood groups A, B and O: their changes associated with human cancer. Biochem. Biophys. Acta 1473; 247-266.

15. Imam, A., Yoshida, S. O. and Taylor, C. R. (1988) Distinguishing tumour cells of mammary from extramammary Paget's disease using antibodies to two different glycoproteins from human milkfat-globule membrane. Br. J. Cancer 58; 373-378.

16. Kageshita, T., Egawa, K., Nagano, H., Ono, T., Arao, T. and Nakajima, T. (1986) Immunohistochemical study of distribution of blood group antigens A, B and $\mathrm{H}$ in normal skin. Nippon Hifuka Gakkai Zasshi 96; 705-710 (in Japanese).

17. Mollicone, R., Le Pendu, J., Bara, J. and Oriol, R. (1986) Heterogeneity of the $\mathrm{ABH}$ antigenic determinants expressed in human pyloric and duodenal mucosae. Glycoconj. J. 3; 187-202.

18. Nakagoe, T., Fukushima, K., Hirota, M., Kusano, H., Ayabe, H., Tomita, M. and Kamihira, S. (1994) An immunohistochemical study of the distribution of blood group substances and related antigens in primary colorectal carcinomas and metastatic lymph node and liver lesions, using monoclonal antibodies against A, B, $\mathrm{H}$ type 2, $\mathrm{Le}^{\mathrm{a}}$, and $\mathrm{Le}^{\mathrm{x}}$ antigens. J. Gastroenterol. 29; 265-275.

19. Nakagoe, T., Nanashima, A., Sawai, T., Tuji, T., Ohbatake, M., Jibiki, M., Yamaguchi, H., Yasutake, T., Ayabe, H., Matuo, T. and Tagawa, Y. (2000) Expression of blood group antigens A, B and $\mathrm{H}$ in carcinoma tisuue correlates with a poor prognosis for colorectal cancer patients. J. Cancer Res. Clin. Oncol. 126; 375382.

20. Nosaka, M., Ishida, Y., Tanaka, A., Hayashi, T., Miyashita, T., Kaminaka, C., Eisenmenger, W., Furukawa, F. and Kimura, A. (2008) Aberrant expression of histo-blood group A type 3 antigens in the vascular endothelial cells in inflammatory site. $J$. Histochem. Cytochem. 56; 223-231.

21. Ørntoft, T. F., Wolf, H., Clausen, H., Dabelsteen, E. and Hakomori, S. (1989) Blood group ABH-related antigens in normal and malignant bladder urothelium: possible structural basis for the deletion of type- 2 chain $\mathrm{ABH}$ antigens in invasive carcinomas. Int. J. Cancer 43; 774-780.

22. Le Pendu, J., Marionneau, S., Cailleau-Thomas, A., Rocher, J., Le Moullac-Vaidye, B. and Clément, M. (2001) ABH and Lewis histo-blood group antigens in cancer. APMIS 109; 9-31.

23. Saida, T. (2002) Extramamary Paget's disease. In "General Rules for Clinical and Pathological Studies on Malignant Neoplasms of the Skin”, 1st ed., ed. by T. Saida, M. Takigawa, A. Yamamoto, T. Tuchida and H. Uhara, Kanehara, Tokyo, pp. 58-71 (in Japanese).

24. Sánchez-Mora, N., Presmanes, M. C., Monroy, V., Aladro, M. H. and Álvarez-Fernández, E. (2007) Expression of histo-blood group antigens in bronchial squamous metaplasia. Eur. Respir. $J$. $29 ; 268-272$.

25. Schoentag, R., Primus, F. J. and Kuhns, W. (1987) ABH and Lewis blood group expression in colorectal carcinoma. Cancer Res. 47; 1695-1700.

26. Szulman, A. E. (1960) The histological distribution of blood group substances A and B in man. J. Exp. Med. 111; 785-800.

27. Urso, C., Paglierani, M. and Bondi, R. (1993) Histologic spectrum of carcinomas with eccrine ductal differentiation (sweatgland ductal carcinomas). Am. J. Dermatopathol. 15; 435-440.

28. Urso, C., Bondi, R., Paglierani, M., Salvadori, A., Anichini, C. and Giannini, A. (2001) Carcinomas of sweat glands: report of 60 cases. Arch. Pathol. Lab. Med. 125; 498-505.

29. de Viragh, P. A., Szeimies, R. M. and Eckert, F. (1997) Apocrine cystadenoma, apocrine hidrocystoma, and eccrine hidrocystoma: three distinct tumors defined by expression of keratins and human milk fat globulin 1. J. Cutan. Pathol. 24; 249-255.

30. Wick, M. R., Goellner, J. R., Wolfe, J. T. 3rd and Su, W. P. (1985) Adnexal carcinomas of the skin. I. Eccrine carcinomas. Cancer $56 ; 1147-1162$.

31. Yamamoto, F., Clausen, H., White, T., Marken, J. and Hakomori, S. (1990) Molecular genetic basis of the histo-blood group ABO system. Nature $345 ; 229-233$.

32. Yotsumoto, S., Tsuyama, S., Tashiro, M. and Murata, F. (1990) Ultrastructural immunocytochemical studies of blood group substances in human eccrine glands. J. Histochem. Cytochem. 38; $1815-1821$.

This is an open access article distributed under the Creative Commons Attribution License, which permits unrestricted use, distribution, and reproduction in any medium, provided the original work is properly cited. 